\title{
ASSESSING THE COGNITIVE COMPLEXITY OF VOCATIONAL VALUE CONSTRUCTS USING THE CAREER GRID: A COMPARISON OF THE EXPRESSED AND SUPPLIED METHODS
}

\section{Wei-Cheng Mau}

A revised career grid procedure assessing vocational constructs is described. The procedures' reliabilities, derived from both expressed and supplied methods, are presented.

Although the repertory grid technique has been applied to vocational counseling for almost 3 decades, and more than 1,000 studies have been generated using this technique (R. A. Neimeyer, Baker, \& Neimeyer, 1990), its practical uses seem to be limited by its time-consuming administration procedure and complex scoring tasks. Studies of the reliability and the validity of the measures yielded by grid methods are surprisingly rare. The purpose of this article is twofold: (a) to describe a simplified version of the career grid procedure, and (b) to present research findings based on the use of this revised procedure in relation both to scores yielded through differing methods of grid administration and to gender differences. 


\section{BACKGROUND}

The career grid originated from George Kelly's (1955) person construct theory. Central to this theory is that each individual has his or her own unique ways of constructing events or experiences. In the vocational context, it is assumed that people differ from each other in the construction of their world of work or vocationally related events. Bannister and Mair (1968) defined a grid technique as "any form of sorting test which allows for the assessment of relationships between constructs, and which yields these primary data in matrix form" (p. 136). The grid method can be briefly described as a method of quantifying and statistically analyzing relationships among the constructs used by individuals in framing their career decisions.

Administering the career grid procedure typically consists of three steps: (a) eliciting elements, (b) eliciting constructs, and (c) rating each element along each construct. In the first step, clients are usually provided with a list of elements, for example, occupations such as "Farmer," "Machine Operator," "Architect," and so on. The second step involves eliciting constructs in which a triad of three elements is presented to clients and they are asked to think of some important way in which two of these elements are similar to one another and different from the third. The perceived similarities and differences are recorded verbatim as a single bipolar construct; for example, much education-little education. This process is repeated until 12 constructs are elicited. The third step involves asking clients to rate each element along each of the constructs using a 7-point Likert-type scale (+3 to -3$)$. This process is repeated until clients complete the ratings of all corresponding cells between elements and constructs.

The grid technique provides several measures, which vary from such simple descriptive statistics as the percentage of positive ratings in the matrix, to relatively complex cluster or principle component analyses. Due to space limitations, a description of all of these measures is not possible. Cochran

(1983) and G. Neimeyer (1989) described various indices provided by the grid method, and various scoring procedures are described by Fransella and Bannister (1977). Computer software packages are also available for various scoring methods (e.g., Chambers \& Grice, 1986; Landfield \& Schmittdiel, 1983; Sewell, Mitterer, AdamsWebber, \& Cromwell, 1991).

\section{Variations of Grid Methods}

Since the introduction of the grid method, various forms and procedures have been used in research and clinical assessment. The most common variation involves the procedure by which the grid test is administered. For example, Bodden (1970) developed an instrument that contains a standardized set of vocational constructs. This procedure deviates from personal construct theory in that both occupations and occupational constructs are supplied for the individuals. The major advantage of this procedure is the reduction of errors likely to be introduced by the elicited method (G. Neimeyer \& Leso, 1992). In career assessment, individuals are often supplied with work-related constructs for making an educational or vocational decision. Most of the career exploration systems use a standard set of constructs for developing occupational databases. The advantages of this method, the supplied method, lie not only in its quick administration, but also in the fact that the standardized list of constructs provides a basis for nomothetic comparison of different populations. This supplied method had been commonly used in research, and is now the standard in the literature (G. Neimeyer \& Leso, 1992). 
Regardless of these advantages, the usefulness and generalizability of the supplied method have been questioned (Brown, 1987; Cochran, 1988). The major disadvantage of this method is that the constructs are not universally defined, and the same construct may have different meanings to different individuals. Participants must have an understanding of the constructs, otherwise, an inaccurate listing of occupations might be searched. Also, the constructs considered important by participants may not be included in the standard list.

Another method developed by Cochran (1983) used a procedure that required participants to use their own chosen occupations and constructs. This procedure differed from the elicited method in that both the elements (occupations) and the constructs (values) were explicitly expressed by participants, whereas in the elicited method, the constructs were derived from the method of triads. This method seems to have some appeal in terms of fast administration, while at the same time allowing individuals to use their own personal constructs. However, this method is also criticized as being limited in validity and generalizability. Krieshok, Arnold, Kuperman, and Schmitz (1986) indicated that the major flaw in the expressed method is that both the occupations and the values constituted the top end of participants' range of interests. The restricted range of values results in introducing a significant degree of error in computing the correlation coefficients. Despite this criticism, Cochran (1988) maintained that personal meaningfulness should be the primary concern for practitioners. He criticized the supplied method as a "laboratory artifact that has no practical application, and possibly no theoretical significance" (p. 209).

\section{The Revised Grid Procedure}

Considering the lengthy administration and the complex scoring task of the traditional grid methods, I attempted to simplify previous grid procedures. The revised grid procedure is illustrated in the Method section. The changes and the merits of these changes are also discussed in the Method sections.

One advantage of the revised grid procedure, in addition to assessing vocational constructs, is its use as a career exploration tool. The revised grid procedure can be treated as a simplified version of the subjective expected utility decision model, as described by Gelatt (1962) and Katz (1966). According to the subjective expected utility model, a best decision is made based on the choice of the alternative that maximizes all of the important valences or values. Mau and Jepsen (1992) have developed an interactive computer program to compute the expected utilities for career decision making. The computation procedure is also described in the Method section.

\section{Elicited Versus Supplied Methods}

There is considerable evidence that constructs that are elicited individually from participants are more personally meaningful to them than are constructs supplied to them (Adams-Webber, 1979; Brown, 1987). For example, Bonarius (1965) showed that participants consistently ranked the constructs elicited from themselves as more useful than constructs elicited from the "target" in describing a particular acquaintance. Comparing the supplied and elicited constructs in career evaluation, Cochran (1977) indicated that the elicited constructs were more interrelated, and more evaluatively compatible, than were the supplied constructs. More recent research in vocational psychology has also consistently shown that the elicited method yields a higher level of construct differentiation than does the supplied method (Brown, 1987; Cochran, 1977; G. J. Neimeyer, Brown, Metzler, Hagans, \& Tanguy, 1989; G. Neimeyer \& Metzler, 1987). 
Although differences between the elicited and supplied methods have been extensively studied (see AdamsWebber (1979) and G. Neimeyer (1988) for reviews), very few studies have compared the reliability of these two approaches in the career context. Only one study that I retrieved has compared the test-retest reliabilities of the expressed, the elicited, and the supplied methods. In their reliability study, Krieshok et al. (1986) found that the elicited method was superior to the expressed method, whereas the supplied method yielded the lowest reliability coefficients. Based on the fact that the expressed and supplied methods were relatively low in reliability, these authors suggested that these two methods may be ineffective for measuring value constructs. Further reliability evidence is needed for these revised grid procedures.

The purpose of this study was to describe and provide reliability evidence of a revised career grid that I created. Specifically, this study compares differences between the supplied and the expressed methods regarding their yielded scores for choice consistency, integration, and differentiation. Gender differences in vocational construct systems have also been a topic of investigation (Bodden, 1970; Brown, 1987; G. Neimeyer \& Metzler, 1987; Parr \& Neimeyer, 1994). Research has indicated that men show a higher level of differentiation than do women, regardless of the use of the elicited or supplied methods. However, Brown (1987) found that men showed significantly greater differentiation than did women only when constructs were elicited. Because of these mixed results, this study also examined the relationship between gender and grid types. The research questions addressed in this study were (a) Is there a difference in test-retest reliability between the supplied and the expressed methods when the revised career grid procedure is used; (b) Does the expressed method yield higher scores on value integration, value differentiation, and choice consistency than the supplied method; and (c) Are there gender differences in findings relating to value integration, value differentiation, or choice consistency?

\section{METHOD}

Sample

Undergraduate students enrolled in human growth and development classes at a midwestern state university were invited to take part in this study. Of about 150 enrolled students, $146(M=36, F=110$ ) participated. Students enrolled in these classes were primarily junior and senior education majors and included a high proportion of part-time students. The mean age was 25.9 years (SD $=6.8$ ), ranging from 18 to 48 years. The majority of participants (over $90 \%$ ) were Caucasian.

\section{Procedure}

Each participant was randomly assigned to one of two groups: expressed method and supplied method. A career grid with instructions was administered to students. There were three steps involved in the career grid procedure: (1) listing choice possibilities, (2) listing job characteristics, and (3) estimating the likelihood of those job characteristics with each of the corresponding occupations. For the supplied method, participants were asked to choose work-related values from a value checklist that contained 30 values used in The Complete Guide for Occupational Exploration (Farr, 1993). For the expressed method, participants were asked to identify those values that they considered relevant to and important for choosing an occupation. The detailed instructions are in the Appendix.

\section{Instrument}


The differences between the revised grid procedure and other grid methods lie in the procedure for eliciting elements and constructs, and in the rating scale. Instead of providing participants with a standard list of occupations, participants are asked to generate their own list of occupations and to provide their own constructs. As shown in Figure I, the simplified career grid now consists of a $10 \times 10$ matrix in which 10 occupations are rated along a set of 10 value constructs, using a 3-point Likert-type scale $(1=$ unlikely, 2 = likely, and 3 = very likely).

My revised grid procedure seems to have several advantages over other grid procedures. One major advantage is that the revised grid is more manageable. Shortening the rating scale reduces the cognitive burden on the participants. The use of a 3-point scale is designed to minimize the possibility of information overload, a very real possibility on other grids that use a 7-point scale in a $12 \times 12$ grid, for a total rating of 144 . Another advantage is that the simplified grid requires less time in administration. The amount of time for grid administration varies with the form and the size of the grid. On the average, at least 30 minutes are required for a participant to complete a standard grid, whereas the modified grid can be completed in less than 20 minutes.

Cochran (1988) suggested that it is important for people to select their own occupations and constructs because this reflects the actual decisionmaking situation. The revised grid procedure allows individuals to use their own choice of occupations during the grid process, and therefore the exercise becomes more relevant to their decision-making situation. Because of the use of relevant occupations, the grid method becomes a tool not only for assessment purposes but also for career decision making.

As mentioned earlier, the revised career grid can be treated as a simplified version of the subjective expected utility decision model. The expected utility of each alternative can be computed using the formula $E U=E \times V$, where EU represents the expected utility products, E represents the likelihood ratings, and $V$ represents the value ratings. Using Figure 1 (a career grid completed by an undergraduate student) as an example, the EU of each occupation is calculated by summing all of the likelihood ratings multiplied by the value rankings within each occupation. To do this, the value rankings have to be reversed to reflect the weights. In the example, the $\mathrm{EU}$ and the indirect preference rankings (in parenthesis) for each occupation are 159(1), 125(2), 121(3), 116(4.5), 101(6), 82(8), 91(7), 116(4.5), 75(10), and 80(9), respectively. A quick but less precise method to obtain this index entails summing the likelihood ratings within each occupation. The simplified EU and the indirect preference rankings derived from the this simplified method are 27(1), 21(2.5) 19(5.5), 21(2.5), 19(5.5), 16(8), 18(7), 20(4), 13(10), 14(9). The occupation that has the highest EU value is considered the best choice, because this occupation is most likely to maximize all of the occupational values that the decision maker considers important. The order of choice preference can also be evaluated based on many EU values associated with each occupation.

\section{Measures}

Three measures--value integration, value differentiation, and choice consistency-derived from the revised grid and scored for this study are described as follows.

Value integration. This measure indicates the overall strength of correlation among all grid ratings in any given matrix, reflecting the individual's level of integration of vocational constructs (Adams- 
Webber, 1979). This measure of cognitive integration was obtained by calculating the product-moment correlations between each possible pair of value-construct ratings across occupations. In other words, each construct was entered as a variable for correlation analysis. Each correlation coefficient in the correlation matrix was squared and added. An average coefficient was then calculated. Because the procedure allowed participants to list a variable number of constructs, the average coefficient was then weighted based on the number of constructs used. Integration scores can range from 0 (low integration) to 45 (high integration). The score for the case in Figure 1 is 8.24. This indicates low integration ( $M=11.76, S D=6.63)$.

Percentage of variance accounted for by the first factor (PVAFF). The PVAFF, derived from a principal component analysis of the grid ratings, can also be used to approximate the integration measure (Cochran, 1983; Slater, 1977). It is assumed that the larger the first factor, the more unidimensional the underlying structure of the grid (Feixas, Moliner, Montes, Mari, \& Neimeyer, 1981). As with value integration, a greater score indicates greater cognitive integration, and a lower score indicates lower cognitive integration.

Value differentiation. Construct differentiation is considered to be one of the most important factors in career decision making (Cochran, 1983). If a construct does not allows differentiation in ratings, it is useless for decision making, regardless of how important one may think it is. Individuals who manifest high construct differentiation are capable of distinguishing among occupational constructs. whereas individuals with low construct differentiation are said to have difficulty in making distinctions among constructs. The differentiation measure was obtained by calculating the standard deviation of ratings for each value construct. Standard deviations were summed and divided by the number of values (Cochran, 1983). Differentiation scores can range from 0 (low differentiation) to 1 (high differentiation). The score for the case in Figure I is .50. This indicates low differentiation ( $M=.57, S D=.18$ ).

Choice consistency. Consistency refers to the degree of agreement between direct and indirect rankings. Direct rankings are participants' rankings of occupational preferences. Indirect rankings are the rankings based on the sum of likelihood ratings that participants estimated for each occupation and value construct. The sum of ratings for an occupation indicates a rough measure of preference rather than actual preference. Spearman rank-order correlations, a measure of rank agreement, were calculated for this study (Cochran, 1983). Possible score ranges were from -1 to 1 . In the case of the undergraduate student example illustrated in Figure 1, the consistency score is .81. The mean and standard deviation for this total sample are .47 and .39.

\section{Data Analysis}

Individual scores on value integration, differentiation, and consistency were first analyzed using the SPSS-X statistical program (1990). Because the revised grid procedure allowed participants to list a variable number of occupations and constructs, it was necessary to construct various scoring procedures for these revised grid data (the syntax of the computer program is available from the author upon request). Each individual grid was analyzed using the principal factor analysis to produce PVAFF, correlation matrices, row (values) and column (occupations) means, and standard deviations. The correlation matrices were used to compute the integration scores as described in the previous sections. The row means were used to compute the differentiation scores. 
To obtain the choice consistency score, several score transformations took place. First, the average likelihood rating for each occupation was computed. The indirect preference ranking was obtained based on the sum of average ratings. In the event that a tie score occurred, each was assigned the mean of ranks they would otherwise occupy. The indirect preference rankings were then compared with the direct preference ranking using the Spearman rank-order procedure: $r=1-\left[6 *\right.$ sigma $D^{2} /$ $\left.N\left(N^{2}-1\right)\right]$.

The scores obtained from the individual grid were entered as raw data for analyses of group mean differences. Group differences were analyzed using 2-way (Method x Gender) ANOVAs. Because the sample sizes for each cell did not conform to proportionality, the unweighted average of cell means was used (Feldt, 1984).

\section{RESULTS}

One of the major purposes of this study was to compare the expressed and supplied methods regarding their yielded scores for value integration, differentiation, and consistency, along with the number of constructs used. Gender differences were also examined.

Table 1 provides a summary of these findings. Results of the ANOVA indicated no significant main effect in choice consistency for method type, $F(1,140)=1.59, p<.21$; gender, $F(1,140)=.01, p<.92$; or interaction, $F(1$, $140)=1.2, p<.27$. No significant main effect in value integration was found for method type, $F(1,142)=.03, p$ $<.86$; gender, $\mathrm{F}(1,142)=.29, \mathrm{p}<.59$; or interaction, $\mathrm{HI}, 142)=2.92, \mathrm{p}<.09$. Results also indicated no significant differences in value differentiation for method type, $F(1,142)=.07, p<.94$; gender, $F(1,142)=.06, p<.80$; or interaction, $F(1,142)=.58, p<.45$. The only significant difference was found in the number of value constructs used, $F(1,142)=30.55, p<.0001$. Participants in the supplied group used a significantly higher number of values $(M=9.5, S D=1.2)$ than did those in the expressed group $(M=7.8, S D=2.3)$. There were no significant gender differences or interaction effects found for the number of values used.

Table 2 provides test-retest reliabilities based on expressed and supplied methods in a 2-week period. The testretest reliabilities were derived based on a subsample of 36 participants who were randomly selected from the sample group. The expressed method $(r=.74)$ yielded a higher test-retest reliability than did the supplied method $(r=.13)$ for the value integration measure, while the supplied method $(r=.73)$ produced a slightly higher test-retest reliability than did the expressed method $(r=.62)$ on the value differentiation measure. Percentage of variance accounted for by the first factor (PVAFF), an equivalent measure of integration, was also estimated. The expressed method $(r=.93)$ yielded a larger reliability than did the supplied method $(r=.51)$. Both the expressed method $(r=.20)$ and the supplied method $(r=.03)$ yielded low test-retest reliability for the choice consistency measure.

Simple correlations among variables are also presented in Table 2. Integration was significantly associated with differentiation $(r=.22, p<.05)$, number of constructs used $(r=-.23, p<.05)$, and PVAFF $(r=.94, p<.01)$.

\section{DISCUSSION}

Unlike the results obtained in previous studies of the standard elicited method, this study did not indicate that the expressed method was superior to the supplied method. The reasons that the expressed method failed to yield higher integration and differentiation scores are complex and are a 
matter for further investigation. However, I speculate that selecting personal constructs without using the method of triads to elicit personal constructs may be the critical deviation from the elicited method that resulted in a lack of significant differences in this study.

Another possible explanation for the different results is that the sample used in this study was more homogeneous, with participants more advanced in their career development. Participants selected in this sample may have relatively higher abilities in articulating career values than did participants in other studies. Consequently, this may have minimized the differences between the expressed and the supplied[methods. Replications using a different sample would clarify this matter.

Considering the subjective nature of the rating methods, the differentiation measure used in this study seemed to be fairly stable over time regardless of the method type. Although both methods demonstrated a moderate test-retest reliability, the supplied method resulted in a slightly better reliability coefficient than that of the expressed method. Nevertheless, the use of rating standard deviation to represent cognitive differentiation seemed to be reliable.

Although the reliability of the integration measure for the expressed method was sufficiently high, the reliability for the supplied method was surprisingly low. This may be due to the relatively small sample in the supplied group. Nevertheless, the reliability coefficient of PVAFF for the supplied method was moderate. Given the fact that both PVAFF and value integration can be used to measure cognitive complexity (note that a high correlation between the PVAFF and integration measures obtained from this study seemed to support this concept), I suggest that PVAFF may be a better measure of cognitive complexity, because it yielded a more stable score than did the integration measure. The interpretation of the reliability results should be made with caution. Test-retest reliabilities generated from this study were based on a subset of the selected sample, therefore, sampling errors need to be taken into consideration when interpreting data.

Although previous studies have shown gender differences in cognitive complexity regardless of the method types, this study indicated no significant gender difference or method interaction. Again, this may be explained by the fact that participants in this study were junior and senior students in the teacher education program, who tended to have similar vocational constructs and who may have used more finite occupations in construing the career grid. Also, these students were more advanced in their career development and were more cognitively complex, thus minimizing any significant gender differences. Further studies based on crosssectional samples may be needed to clarify this speculation. Limitations of the study should be noted when interpreting the results. Due to the unequal sample size for male students and female students, sampling errors need to be taken into consideration when making generalizations.

Although the supplied method $(r=.53)$ yielded a slightly greater consistency score than did the expressed method $(r=.46)$, in general, students, did not make decisions that were consistent with the vocational values they construed. Only about $28 \%$ of the explanation for the preferences of choice can be attributed to the constructs selected by students in the supplied method, and about $21 \%$ of choice preferences can be explained by the constructs selected by students in the expressed method. Overall, the constructs used by the participants only accounted for a relatively small percentage (25\%) of variance in ranking among identified occupations. This indicates that, in a simulated situation, 
individuals may not identify all the important factors in their decision making. Counselors need to take this inconsistency into consideration in their career counseling with college students. Neither method produced stable choice consistency scores over time.

The only significant difference between the expressed and supplied methods was the number of values students applied to their career decisionmaking task. Students who used the supplied method adopted more values than did those who used the expressed method. Considering the fact that both methods produced similar results, the expressed method seemed to be more efficient because it required fewer values and still produced the same result.

\section{SUMMARY}

The findings of this study showed no significant differences between the supplied and expressed methods in choice consistency, integration, and differentiation. Also, this study did not show significant gender differences in cognitive complexity measures of vocational constructs. Possible explanations were discussed and suggestions for further studies were provided. The results of the reliability studies based on these two methods were also mixed. The expressed method had a higher reliability coefficient on value integration, while the supplied method had a higher reliability coefficient on value differentiation. More reliability and validity studies are needed. As suggested by G. Neimeyer et al.

(1992), it may be "equally unwise to abandon prematurely the advantages of provided constructs (e.g., expediency), or to nurture an uncritical adherence to elicited constructs' (p. 127). The relative advantages of the elicited versus the supplied methods remain an empirical question warranting further attention. However, given the state of current understanding, practitioners might be justified in choosing the procedure they believe most appropriate for each individual client.

TABLE 1 Means and Standard Deviations of Choice Consistency, Value Integration, Value Differentiation, and Number of Values Used by Method and by Sex

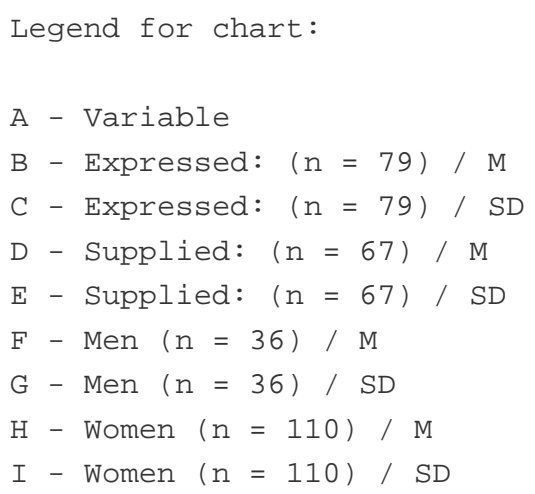


Note. Choice Consistency ranges from -1.0 to 1.0. Value Integration scores ranged from 0.00 to 45.00 . Value Differentiation scores ranged from 0.0 to 1.0 .

\section{TABLE 2 Test-Retest Reliability and Simple Correlations Among Variables}

Legend for Chart:

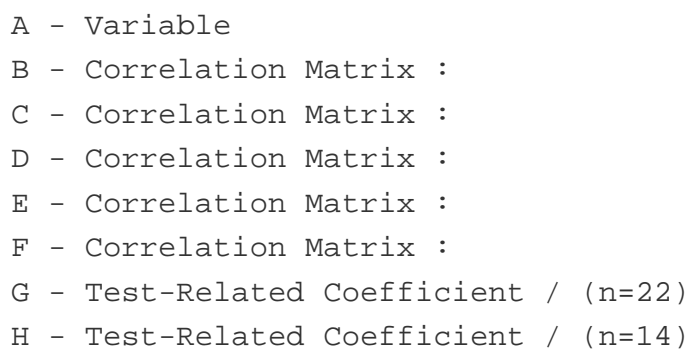

\section{Choice}

Consistency

$\begin{array}{lll}\text { F } & \text { G }\end{array}$

\begin{tabular}{|c|c|c|c|c|}
\hline & & -- & .20 & .03 \\
\hline \multirow[t]{2}{*}{ Value Integration } & -.03 & -- & -- & -- \\
\hline & & -- & $.74[b]$ & .13 \\
\hline \multirow[t]{2}{*}{ Value Differentiation } & .02 & $.22[a]$ & -- & -- \\
\hline & & -- & $.62[\mathrm{~b}]$ & $.73[b]$ \\
\hline \multirow[t]{2}{*}{ No. of Values Used } & .13 & $-.23[a]$ & .14 & -- \\
\hline & & -- & $.81[\mathrm{~b}]$ & .18 \\
\hline \multirow[t]{2}{*}{ PVAFF .20} & $.94[b]$ & .15 & -.09 & -- \\
\hline & & $.93[\mathrm{~b}]$ & .51 & [a] \\
\hline
\end{tabular}

Note. Simple correlation matrix was based on $n=146$. PVAFF $=$ percentage of variance accounted for by the first factor.

[a] $p<.05$. [b]p $<.01,2$-tailed.

\section{FIGURE 1 Illustration of a Revised Career Grid Procedure}

Legend for Chart:

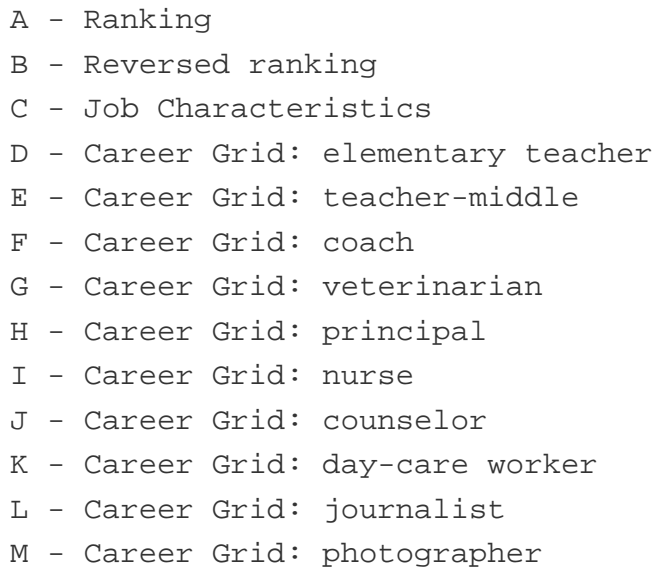


A B

Rankings

101 good money

110 satisfaction

83 weekend/holiday

$\begin{array}{llllllll}2 & 9 & \text { working w/ people } & 3 & 3 & 3 & 2 & 3\end{array}$

38 helping people

learn

65 job stability

47 enjoy what I do

74 supportive workers 2

56 independent setting 3

92 self-direct work

Column sum

27

$6 \quad 18$

19

Rankings

1.0

2.5

5.5

$2.5 \quad 5.5$

8.0

7.0

4.0

10

9.0

Expected Utility

$\begin{array}{rrrrr}159 & 125 & 121 & 116 & 101 \\ 2 & 91 & 116 & 75 & 80\end{array}$

Rankings

$\begin{array}{ll}1.0 & 2.0 \\ 8.0 & 7.0\end{array}$

3.0

4.5

6.0

Ratings:

- 3 = very likely 2

- = Possibly

$1=$ Very unlikely

\section{REFERENCES}

Adams-Webber, J. (1979). Personal construct theory: Concepts and applications. New York: Wiley. 
Bannister, D., \& Mair, J. M. M. (1968). The evaluation of personal constructs. London: Academic Press.

Bodden, J. (1970). Cognitive complexity as a factor in appropriate vocational choice. Journal of Counseling Psychology, 17, 364-368.

Bonarius, J. C. J. (1965). Research in the personal construct theory of George A. Kelly. In B. A. Maher (Ed.), Progress in experimental personality research (Vol. 2). New York: Academic Press.

Brown, M. (1987). A comparison of two approaches to the cognitive differentiation grid. Journal of Vocational Behavior, 30, 155-166.

Chambers, W. V., \& Grice, J. W. (1986). Circumgrids: A repertory grid package for personal computers. Behavioral Research Methods, Instruments, and Computers, 28(5), 468.

Cochran, L. (1977). Difference between supplied and elicited construct: Considerations in career evaluation. Social Behavior and Personality, 5, 241-247.

Cochran, L. (1983). Seven measures of ways that deciders frame their career decisions. Measurement and Evaluation in Guidance, 16, 67-77.

Cochran, L. (1988). Comment on 'articulation of values.' Journal of Counseling Psychology, 35(2), 209-210.

Farr, M. J. (Ed.). (1993). The complete guide for occupational exploration. Indianapolis, IN: Jist Works. Feixas, G., Moliner, J. L., Montes, J. N., Mari, M. T., \& Neimeyer, R. A. (1981). The stability of structural measures derived from repertory grids. International Journal of Personal Construct Psychology, 5, 25-39.

Feldt, L. S. (1984). Design and analysis of experiment. lowa City, IA: University Press.

Fransella, F., \& Bannister, D. (1977). A manual for repertory grid technique. London: Academic Press.

Gelatt, H. B. (1962). Decision-making: A conceptual frame of reference for counseling. Journal of Counseling Psychology, 9, 240-245.

Katz, M. R. (1966). A model of guidance for career decision making. Vocational Guidance Quarterly, 15, 2-10.

Kelly, G. A. (1955). The psychology of personal construct (Vols. 1-2). New York: Norton.

Krieshok, T., Arnold, J., Kuperman, B., \& Schmitz, N. (1986). Articulation of career values: Comparison of three measures. Journal of Counseling Psychology, 33, 475-478.

Landfield, A. W., \& Schmittdiel, C. P. (1983). The interpersonal transaction group: Evolving measurements in the pursuit of theory. In J. R. Adams-Webber \& J. C. Mancuso (Eds.), Applications of personal construct theory (pp. 207-218). Toronto: Academic Press. 
Mau, W. C., \& Jepsen, D. A. (1992). Effects of computer-assisted instruction in using formal decision-making strategies to choose a college major. Journal of Counseling Psychology, 39, 185-192.

Neimeyer, G. J. (1988). Cognitive integration and differentiation in vocational behavior. The Counseling Psychologist, 16(3), 440-475.

Neimeyer, G. J. (1989). Testing the test: Applications of repertory grid technique to vocational assessment. Journal of Counseling and Development, 67, 585-589.

Neimeyer, G. J., Brown, M. T., Metzler, A. E., Hagans, C., \& Tanguy, M. (1989). The impact of sex, sex-role orientations, and construct type on vocational differentiation, integration, and conflict. Journal of Vocational Behavior, 34, 236-251.

Neimeyer, G. J., Leso, J. (1992). Effects of occupational information on personal versus provided constructs: A second look. Journal of Counseling Psychology, 39, 331-334.

Neimeyer, G. J., Leso, J., Marmarosh, C., Prichard, S., \& Moore, M. (1992). The role of construct type in vocational differentiation: Use of elicited versus provided dimensions. Journal of Counseling Psychology, 39, 121-128.

Neimeyer, G. J., \& Metzler, A. (1987). The development of vocational schemas. Journal of Vocational Behavior, 30, 16-32.

Neimeyer, R. A., Baker, K., \& Neimeyer, G. J. (1990). The current status of personal construct theory: Some scientometric data. In G. J. Neimeyer \& R. A. Neimeyer (Eds.), Advances in personal construct theory (Vol. 1, pp. 3-22). Greenwich, CT: JAI.

Parr, J., \& Neimeyer, G. J. (1994). Effects of gender, construct type, occupational information, and career relevance on vocational differentiation. Journal of Counseling Psychology, 41, 27-33.

Sewell, K. W., Mitterer, J., Adams-Webber, J., \& Cromwell, R. L. (1991). Omnigrid-PC: A new development in computerized repertory grids. International Journal of Personal Construct Psychology, 4, 175-192.

Slater, P. (1977). Dimensions of interpersonal space. New York: Wiley.

SPSS-X. (1990). SPSS base system user's guide. Chicago: Mavija Norusis/SPSS.

\section{APPENDIX}

\section{Instructions for Completing the Career Grids}

I. Career Grid: Expressed Method

Procedure: This is the procedure for completing the Decision Grid worksheet on the following page.

Step 1. Listing Choice Possibilities

A. Please try to list up to 10 occupations that you might like to enter regardless of your training or education. Write these occupations in the 'Choice Possibilities" section of the grid, one per box. 
B. Rank the occupations in order of your preferences with 1 as first preference and so on for all the occupations you listed. Enter these rankings by each occupation in the "Choice Possibilities" section.

\section{Step 2. Listing Job Characteristics}

A. Occupations have many characteristics that distinguish one from an other. For example there are different requirements, routines, and rewards that one needs to consider before choosing among occupations. In the 'Job Characteristics" section, list as many characteristics as you can, up to 10 that you consider important in choosing occupations.

B. Rank these characteristics in order of importance to you from I as the most important and so on for all characteristics you listed. Enter these rankings by each characteristic in the 'Job Characteristics" section.

\section{Step 3. Estimating Likelihood}

A. Begin with the first column and first row on the top left corner of the grid and continue working from left to right within the first row. Rate every occupation on the first characteristic using a 3-point scale $(1=$ very unlikely, 2 = possible, and 3 = very likely).

B. Continue on the second row working with the next characteristic and so on for each of the remaining characteristics until all occupations and characteristics are rated.

II. Career Grid: Supplied Method

Procedure: This is the procedure for completing the "Decision Grid" worksheet on the following page. Step 1. Listing Choice Possibilities

A. Please try to list up to 10 occupations that you might like to enter regardless of your training or education. Write these occupations in the 'Choice Possibilities" section of the grid, one per box.

B. Rank the occupations in order of your preferences from 1 as first preference and so on for all the occupations you listed. Enter these rankings by each occupation in the 'Choice Possibilities" section.

Step 2. Listing Job Characteristics

A. Occupations have many characteristics that distinguish one from another. For example there are different requirements, routines, and rewards that one needs to consider before choosing among occupations. From the 'Work-Related Characteristics Checklist,' choose 10 Characteristics that you feel would be important for you to have in a future job. In the "Job Characteristics' section, list as many characteristics as you can (up to 10) that you consider important in choosing occupations.

B. Rank these characteristics in order of importance to you. from 1 as the most important and so on for all characteristics you listed. Enter these rankings by each characteristics in the 'Job Characteristics' section. 
A. Begin with the first column and first row on the top left corner of the grid and continue working from left to right within the first row. Rate every occupation on the first characteristic using a 3-point scale $(1=$ very unlikely, 2 = possible, and 3 = very likely).

B. Continue on the second row working with the next characteristic and so on for each of the remaining characteristics until all occupations and characteristics are rated. 